\title{
Fluorescent diagnostics of benign breast diseases and breast cancer
}

\author{
Valeriya S. Maryakhina ${ }^{1 *}$, Yulia S. Korneva ${ }^{2,3}$, Igor V. Chekurov ${ }^{4}$, and Oksana A. Shisterova ${ }^{5}$ \\ ${ }^{1}$ Kumertau branch of Orenburg State University, 3b 2nd Sovetski av., Kumertau 453300, Russia \\ ${ }^{2}$ Smolensk State Medical University, 28 Krupskoy st., Smolensk 214019, Russia \\ ${ }^{3}$ Smolensk Regional Institute of Pathology, 27 Gagarina st., Smolensk 214020, Russia \\ ${ }^{4}$ Orenburg State Agriculture University, 18 Chelyuskintsev st., Orenburg 460014, Russia \\ ${ }^{5}$ Smolensk Oncological Dispensary, 19 Zhukova st., Smolensk 214000, Russia \\ *e-mail: valemar@mail.ru
}

\begin{abstract}
In the study the spectra of fluorescence excitation and autofluorescence of histological sections with different pathological processes in breast were measured. Additionally, element composition of the tissues was investigated by scanning electron microscopy. It has been shown that spectra of fluorescence excitation of benign breast diseases (fibroadenoma and fibrocystic breast disease) have low maximum at $232 \mathrm{~nm}$ and high maximum at $260 \mathrm{~nm}$. Also, fluorescence spectra of histological samples change during tumor growth and have two maxima (335 and $420 \mathrm{~nm}$ ). The registered spectra are result of emission of such fluorophores as fatty acids, tryptophan, NADH, vitamin B6, collagen and bilirubin. The obtained spectral data correlate well with data of element analysis. Selenium status of the tissues was investigated by scanning electronic microscope. High concentration if selenium was detected only in fibroadenoma. In breast cancer samples and fibrocystic breast disease low selenium content was detected. It may confirm higher risk for malignant transformation of fibrocystic breast disease than fibroadenoma. Our results may be helpful for cancer diagnostics and for prognosis prediction. (C) 2017 Journal of Biomedical Photonics \& Engineering.
\end{abstract}

Keywords: breast cancer; benign breast disease; fluorescence; optical biomedical diagnostics.

Paper \#3271 received 1 Dec 2017; revised manuscript received 19 Dec 2017; accepted for publication 20 Dec 2017; published online 31 Dec 2017. doi: 10.18287/JBPE17.03.040306. [Saratov Fall Meeting 2017 Special Issue].

\section{References}

1. C. E. DeSantis, J. Ma, S. A. Goding, L. A. Newman, and A. Jemal, "Breast cancer statistics, 2017, racial disparity in mortality by state," CA: a Cancer Journal of Clinicians 67(6), 439-448 (2017).

2. S. Winters, C. Martin, D. Murphy, and N. K. Shokar, "Breast Cancer Epidemiology, Prevention, and Screening," Progress in Molecular Biology and Translational Science 151, 1-32 (2017).

3. V. Marco, T. Muntal, F. García-Hernandez, J. Cortes, B. Gonzalez, and I. T. Rubio, "Changes in breast cancer reports after pathology second opinion,” The Breast Journal 20(3), 295-301 (2014).

4. C. Colin, M. Devouassooux-Shisheboran, and F. Sardanelli, "Is breast cancer overdiagnosis also nested in pathologic misclassification?” Radiology 273(3), 652-655 (2014).

5. L. F. Carvalho, F. Bonnier, K. O'Callaghan, J. O'Sullivan, S. Flint, H. J. Byrne, and F. M. Lyng, "Raman micro-spectroscopy for rapid screening of oral squamous cell carcinoma," Oral Surgery, Oral Medicine, Oral Pathology and Oral Radiology 119(3), e106-e107 (2015).

6. M. G. Müller, T. A. Valdez, I. Georgakoudi, V. Backman, C. Fuentes, S. Kabani, N. Laver, Z. Wang, C. W. Boone, R. R. Dasari, S. M. Shapshay, and M. S. Feld, "Spectroscopic detection and evaluation of morphologic and biochemical changes in early human oral carcinoma," Cancer 97(7), 1681-1692 (2003). 
7. A. M. Badowska-Kozakiewicz, M. P. Budzik, and J. Przybylski, "Hypoxia in breast cancer," Polish Journal of Pathology 66(4), 337-346 (2015).

8. O. I. Alatise, O. O. Babalola, G. O. Omoniyi-Esan, O. O. Lawal, A. R. Adesunkanmi, and E. A. Agbakwuru, "Selenium levels in neoplastic breast lesions," The Nigerian Postgraduate Medical Journal 20(2), 91-97 (2013).

9. L. C. Hartmann, T. A. Sellers, M. H. Frost, W. L. Lingle, A. C. Degnim, K. Ghosh, R. A. Vierkant, S. D. Maloney, V. S. Pankratz, D. W. Hillman, V. J. Suman, J. Johnson, C. Blake, T. Tlsty, C. M. Vachon, L. J. Melton 3rd, and D. W. Visscher, "Benign breast disease and the risk of breast cancer," The New England Journal of Medicine 353, 229-237 (2003).

10. Y. Choi, E. Hyun, J. Seo, C. Blundell, H. C. Kim, E. Lee, S. H. Lee, A. Moon, W. K. Moon, and D. Huh, “A microengineered pathophysiological model of early-stage breast cancer," Lab on a Chip 15(16), 3350-3357 (2015).

11. T. Hasebe, "Tumor-stromal interactions in breast tumor progression - significance of histological heterogeneity of tumor-stromal fibroblasts," Expert Opinion on Therapeutic Targets 17(4), 449-460 (2013).

12. J. T. Li, H. W. Zhang, X. H. Guo, X. F. Sun, Y. N. He, C. J. Liu, S. D. Cui, and H. Liu, "Effects of high glucose on in vitro invasiveness of human breast cancer cell line MDA-MB-435," Zhonghua Yi Xue Za Zhi 93(2), 89-92 (2013) [in Chinese].

13. V. S. Maryakhina, The optical techniques in chemistry, biology and medicine, Science, Moscow (2015) [in Russian].

14. R. R. Anderson, and J. A. Parrish, "Optical Properties of Human Skin," in The Science of Photomedicine. Photobiology, J. D. Regan, J. A. Parrish (Eds.), Springer, Boston, 147-194 (1982).

15. G. Deliconstantinos, V. Villiotou, J. C. Stavrides, N. Salemes, and J. Gogas, "Nitric oxide and peroxynitrite production by human erythrocytes: a causative factor of toxic anemia in breast cancer patients," Anticancer Research 15(4), 1435-46 (1995).

16. F. Kebers, J. M. Lewalle, J. Desreux, C. Munaut, L. Devy, J. M. Foidart, and A. Noël, "Induction of endothelial cell apoptosis by solid tumor cells," Experimental Cell Research 240 (2), 197-205 (1998).

17. H. Zeng, C. MacAulay, B. Palcic, and D. I. McLean, "Spectroscopic and microscopic characteristics of human skin autofluorescence emission," Photochemistry and Photobiology 61(6), 639-645 (1995).

18. S. Udenfriend, B. Horecker, N. O. Kaplan, and J. Marmur, "Vitamins, coenzymes, and their metabolites," in Fluorescence assay in biology and medicine, Academic Press Inc., 219-334 (1969).

19. G. Vinothini, C. Aravindraja, K. Chitrathara, and S. Nagini, "Correlation of matrix metalloproteinases and their inhibitors with hypoxia and angiogenesis in premenopausal patients with adenocarcinoma of the breast," Clinical Biochemistry 44(12), 969-974 (2011).

20. C. Potera, D. P. Rose, and R. R. Brown, "Vitamin B6 deficiency in cancer patients," The American Journal of Clinical Nutrition 30(10), 1677-1679 (1977).

21. G. Lurie, L. R. Wilkens, Y. B. Shvetsov, N. J. Ollberding, A. A. Franke, B. E. Henderson, L. N. Kolonel, and M. T. Goodman, "Prediagnostic plasma pyridoxal 5'-phosphate (vitamin b6) levels and invasive breast carcinoma risk: the multiethnic cohort," Cancer Epidemiology, Biomarkers \& Prevention 21(11), 1942-1948 (2012).

22. N. Babaknejad, F. Sayehmiri, K. Sayehmiri, P. Rahimifar, S. Bahrami, A. Delpesheh, F. Hemati, and S. Alizadeh, "The relationship between selenium levels and breast cancer: a systematic review and metaanalysis," Biological Trace Element Research 159(1-3), 1-7 (2014).

23. J. X. de Miranda, F. O Andrade, A. Conti, M. L. Dagli, F. S. Moreno, and T. P. Ong, "Effects of selenium compounds on proliferation and epigenetic marks of breast cancer cells," Journal of Trace Elements in Medicine and Biology 28(4), 486-91 (2014).

\section{Introduction}

Mortality and morbidity of breast cancer (BC) increase annually all over the World [1]. Survival of the patients is strongly associated with timely and high-quality diagnostics, the main goal of which is to detect tumor at early stage or to prevent malignant transformation of precancerous lesions [2]. Biopsy is considered to be mandatory procedure for verification of all pathological processes in breast, suspicious for cancer. Unfortunately, not all cases may be verified easily and unambiguously, especially if it is very small specimen of tissue, obtained through fine-needle or core biopsy
$[3,4]$. For histological sections of such difficult cases spectral techniques may become a new additional tool for investigation due to their high sensitivity.

Benign and malignant pathological processes in any organ differ not only by their histological structure, but also by different biochemical composition due to activation of catabolism and proliferative activity of the cells [5]. For example, due to tumor growth NADH concentration always increases [6], peptide and oxygen concentration decreases [7]. Also it is known that selenium level is low in malignant tumors [8] and this microelement has protective effect against cancer. 
Biochemical proximity of benign pathological process in breast to biochemical composition of malignant tumor may explain its role in cancerogenesis or in some way may be helpful for patient prognosis prediction.

The aim of this study is to investigate spectral characteristics of benign breast disease (BBD) and breast cancer $(\mathrm{BC})$ at different stages for improvement of the optical techniques of biomedical diagnostics.

\section{Materials and methods of the research}

\subsection{Object of research}

The objects of the investigation were tissue specimens from 86 women with different pathological processes in breast (average age $40 \pm 5$ years), treated in Smolensk Regional Oncological Dispensary during 2016. In the group of $\mathrm{BBD}$ cases of fibroadenoma (FA) and fibrocystic breast disease (FCBD) were included as diseases with minimal potential for malignant transformation [9]. The volume of operation was defined according to diagnosis, detected previously by core biopsy. Before operation all the patients singed an informed consent. The investigation was carried out with the agreement of ethical committee of Smolensk State Medical University. All the samples, obtained from surgically removed material, were treated with traditional histological paraffin-embedded technique. Tissue samples were put in $10 \%$ formalin for 24 hours at room temperature. Next, process for paraffin embedding schedule as following and performed in appropriate embedding cassettes: $70 \%$ Ethanol, two changes, 1 hour each; $80 \%$ Ethanol, one change, 1 hour; 95\% Ethanol, one change, 1 hour; $100 \%$ Ethanol, three changes, 1.5 hour each; Xylene or xylene substitute (i.e. Clear Rite 3), three changes, 1.5 hour each; Paraffin wax $\left(58-60{ }^{\circ} \mathrm{C}\right)$, two changes, 2 hours each; embedding tissues into paraffin blocks.

Table 1 Distribution of the cases in the groups according to diagnosis.

\begin{tabular}{cc}
\hline Diagnosis & Amount \\
\hline Fibroadenoma & 14 \\
\hline Fibrocystic breast disease & 21 \\
\hline Cancer I stage & 12 \\
\hline Cancer II stage & 23 \\
\hline Cancer III stage & 16 \\
\hline
\end{tabular}

Two parallel sections $7 \mu \mathrm{m}$ in thickness were done, one of them was stained with hematoxylin and eosin and was investigated by pathologist for the diagnosis verification. Subdivision of the samples according to their diagnosis is shown in Table 1. The group of material from the patients with IV stage were absent in the investigation, because on this stage radical operation is not performed.

\subsection{Fluorimetry}

All histological sections without hematoxylin and eosin staining were placed on quartz glass and proceed by hexane for dewaxing. The unstained samples were used for experiment purity. Spectra of fluorescence excitation were measured on spectrofluorimeter SOLAR CM-2203 (Belarus) with additional equipment for measuring solid samples. Wavelength of registration was $410 \mathrm{~nm}$ after its excitation in UV region. Additionally, fluorescence spectra were measured. Wavelength of excitation was $300 \mathrm{~nm}$. The diameter of sample excitation was $1 \mathrm{~cm}$ that is more then diameter of histological section. For the reason the obtained signal is total signal from all surface of sample.

\subsection{Scanning electronic microscopy (SEM)}

The microstructure of all dewaxed in hexane specimens was examined by scanning electronic microscope JEOL-6000 (Japan). The distribution of microelements (nitrogen, oxygen, carbon, selenium, sulfur) and their quantitative analysis were carried out under high vacuum with voltage $10 \mathrm{kV}$. We note, that we didn't measure absolute concentrations of chemical compounds, as all the samples have been possessed by paraffin-embedded technique and dewaxing, but compare samples from different pathologies of breast, that were prepared in the same way.

\subsection{Statistical analysis}

For statistical analysis (to compare elements concentration in the groups) non-parametrical criterion - Kruskal-Wallis test $(\mathrm{H})$ - was used to compare multiple independent groups. The data were considered statistically significant when $\mathrm{p}<0.05$.

\section{The results and their discussions}

It is well known that tumors are characterized by different types of atypism, one of them is biochemical, that can be detected on spectra of fluorescence excitation from histological sections (Fig. 1). The spectra have several maxima at $233 \div 236,259 \div 268$, $290 \div 335 \mathrm{~nm}$. But all cases of BBD are characterized by three maxima when $\mathrm{BC}$ samples have four peaks. For their analysis the spectra were splitted by Gauss-Lorentz curves method on spectral components (Figs. 1b-1f). For every spectrum the square under the curve was calculated (Table 2). For better visualization the spectra were normalized on the maximum $330 \mathrm{~nm}$. For this reason, squares of spectra components were analogically normalized on the square of curve with maximum $330 \mathrm{~nm}$.

Cases of BBD have the smallest square under curve at $230 \mathrm{~nm}$. The maximum is characterized by fatty acids absorption, that is the main constituent of adipose tissue in normal breast tissue and almost absent in fibrous stroma of FA and FCBD. This square is larger for BC on the $1^{\text {st }}$ stage, as on this stage the normal 


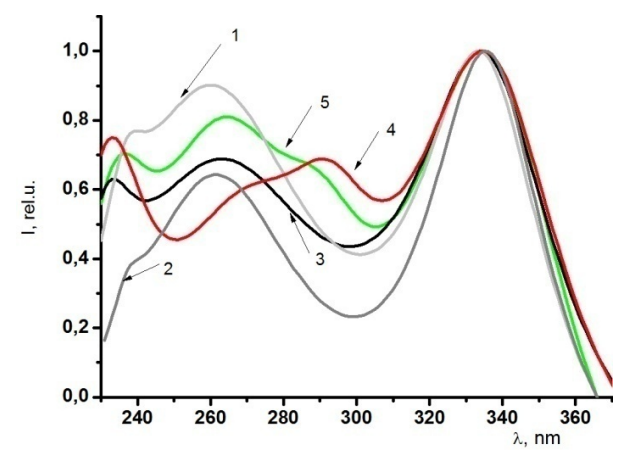

a)

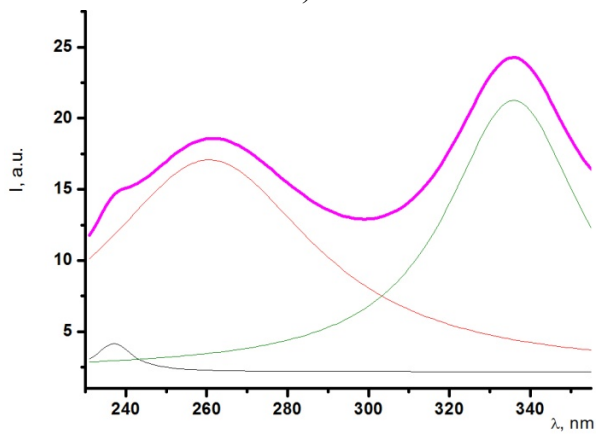

c)

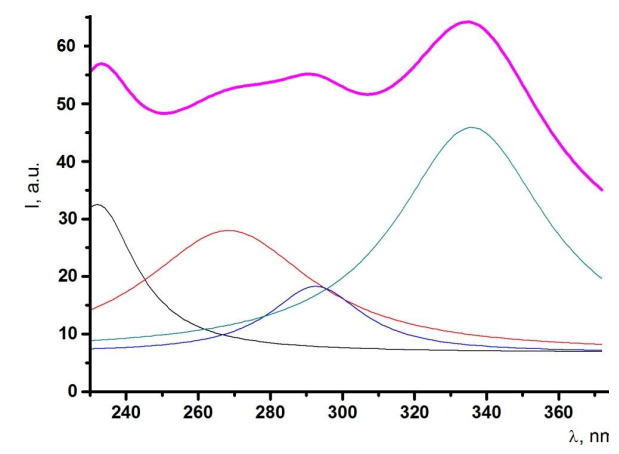

e)

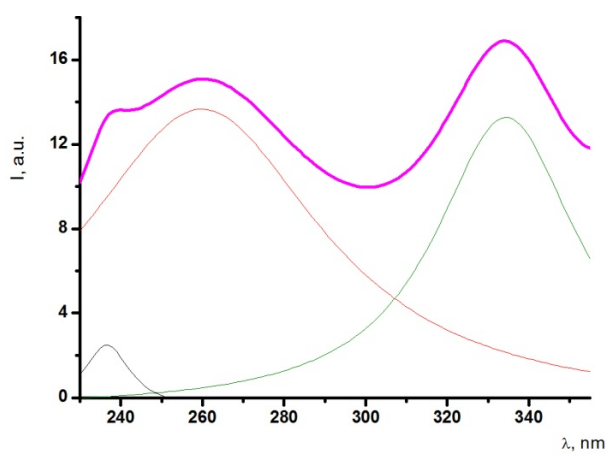

b)

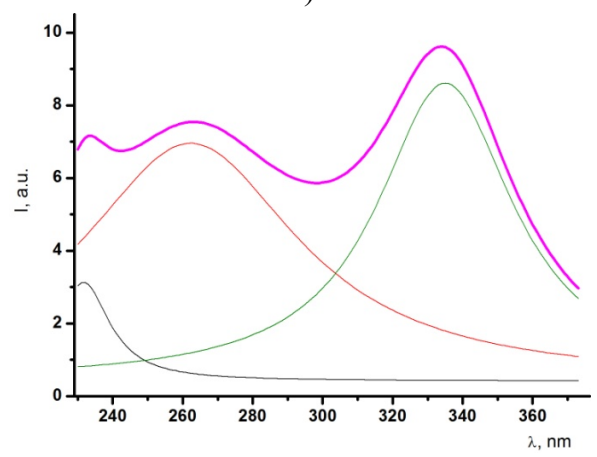

d)

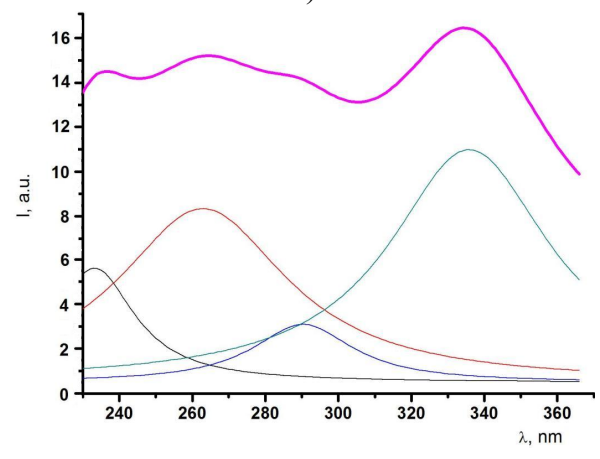

f)

Fig. 1 The typical spectra of fluorescence excitation (a) of histological sections of different pathological processes in breast and their splitted curves. 1- FA (b), 2- FCBD (c), 3- stage I BC (d), 4- stage II BC (e), 5- stage III BC (f). Wavelength of fluorescence registration was $410 \mathrm{~nm}$.

Table 2 The squares under the curves and wavelengths of fluorescence maxima of each group of fluorophores after excitation fluorescence spectra splitting into by Gauss-Lorentz curves method.

\begin{tabular}{|c|c|c|c|c|c|c|c|c|}
\hline & \multicolumn{2}{|c|}{ Peak 1} & \multicolumn{2}{|c|}{ Peak 2} & \multicolumn{2}{|c|}{ Peak 3} & \multicolumn{2}{|c|}{ Peak 4} \\
\hline & $\lambda, \mathrm{nm}$ & $\mathrm{S} / \mathrm{S}_{\max 4}$ & $\lambda, \mathrm{nm}$ & $\mathrm{S} / \mathrm{S}_{\max 4}$ & $\lambda, \mathrm{nm}$ & $\mathrm{S} / \mathrm{S}_{\max 4}$ & $\lambda, \mathrm{nm}$ & $\mathrm{S} / \mathrm{S}_{\max 4}$ \\
\hline FA & 236 & 0.074 & 259 & 1.74 & - & - & 334 & 1 \\
\hline FCBD & 238 & 0.027 & 261 & 1.22 & - & - & 336 & 1 \\
\hline Stage I BC & 232 & 1.59 & 262 & 0.6 & - & - & 334 & 1 \\
\hline Stage II BC & 232 & 0.33 & 268 & 0.67 & 292 & 0.18 & 335 & 1 \\
\hline Stage III BC & 233 & 0.24 & 262 & 0.78 & 290 & 0.15 & 335 & 1 \\
\hline
\end{tabular}




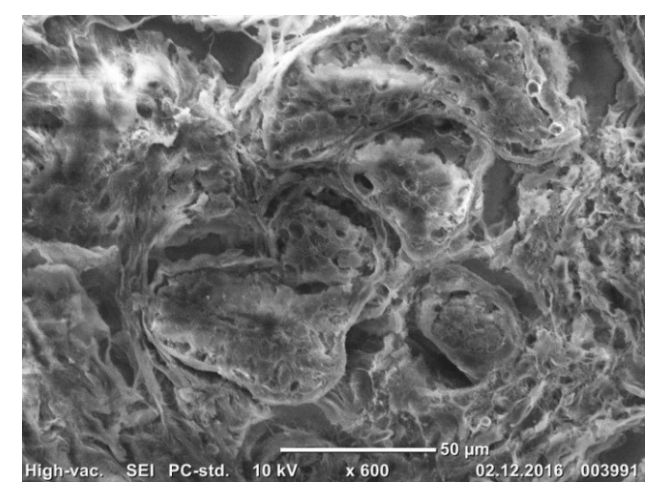

a)

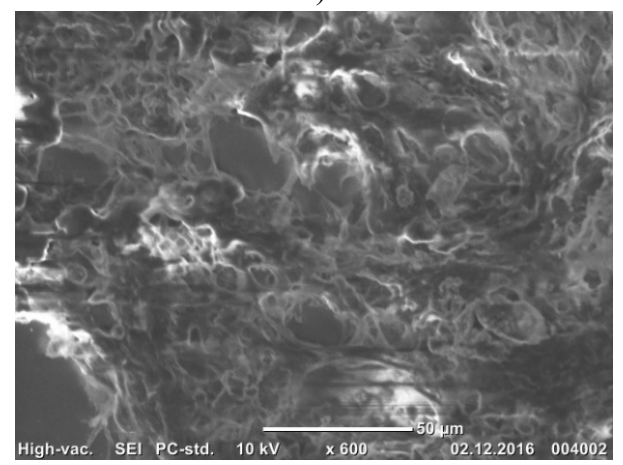

c)

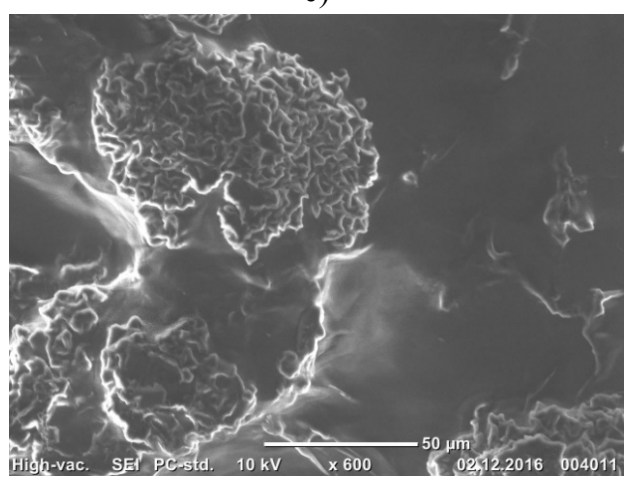

e)

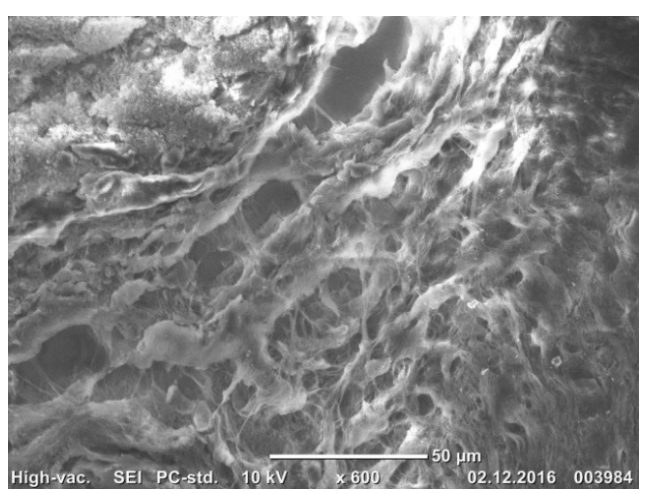

b)

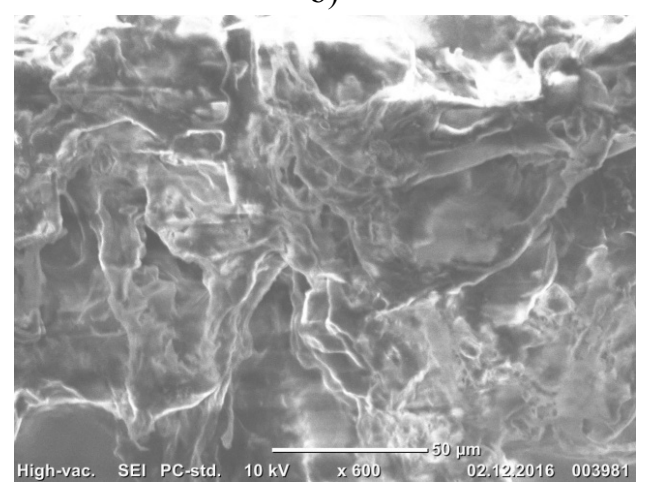

d)

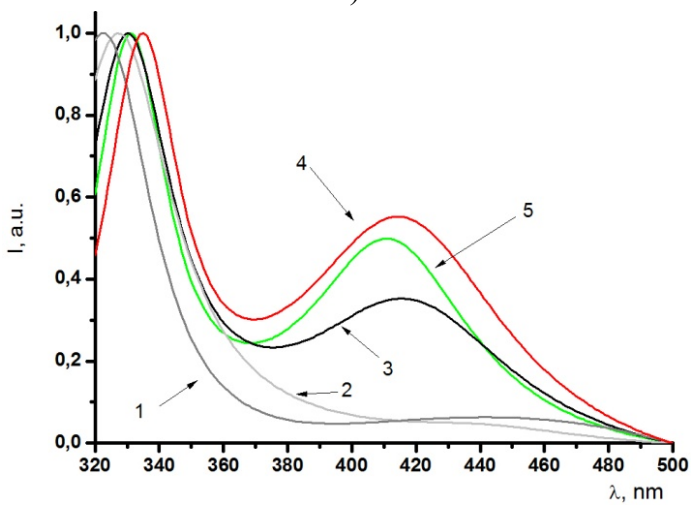

f)

Fig. 2 The typical photo of SEM and fluorescence spectra (f). 1 - FA (a), 2 - FCBD (b), 3 - stage I BC (c), 4 - stage II BC(d), 5 - stage III BC (e). Wavelength of fluorescence excitation was $300 \mathrm{~nm}$.

breast tissue is not damaged remarkably due to changed microenvironment [10]. Further progression of cancer (II and III stages) leads to decreasing absorption of fatty acids, because adipose tissue is replaced by fibrous tissue due to desmoplasia [11] and increased catabolism (the square of the maximum at III stage is 10 times higher than the same parameter for BBD). According to the element analysis (Table 3), the carbon concentration, that characterizes quantity of organic compounds, is higher in groups of $\mathrm{BC}$ in spite of fatty acids concentration decrease. It may be due to higher concentration of carbohydrates (but not proteins) because concentration of nitrogen and sulphur, related to amino acids concentration, in all groups of $\mathrm{BC}$ is remarkably lower than in BBD. It is known, that higher concentration of glucose increases invasiveness of cancerous cells, that is the reason for cancer progression to more advanced stage [12].

The second maximum of these spectra is nearly at $260 \mathrm{~nm}$, but it is higher for BBD, especially for FA. The peak is characterized by presence of tryptophancontaining peptides [13]. BC on the $1^{\text {st }}$ stage is remarkably smaller square under the curve with maximum nearly at $260 \mathrm{~nm}$. Due to progression from stage I to stage III the peak increases by $30 \%$, but it is twice smaller, than in the group of BBD.

Cases with $2^{\text {nd }}$ and $3^{\text {rd }}$ stage of BC have additional peculiarity on their spectra - maximum at $290 \mathrm{~nm}$. The peak is result of bilirubin presence [14] - the product of hemoglobin breakdown. Deposition of it in tissue of BC on later stages may be associated with hemolysis of erythrocytes due to changes in their membrane and 
Table 3 Element composition of tissue with different pathological processes in breast and their comparison by KruskalWallis test.

\begin{tabular}{llllll}
\hline & \multicolumn{5}{c}{ Elements and their concentrations } \\
\hline Diagnosis & W(C), $\%$ & W(N), $\%$ & W(O), $\%$ & W(S), $\%$ & W(Se), \% \\
& Rank sum & Rank sum & Rank sum & Rank sum & Rank sum \\
\hline FA & 87.65 & 4.60 & 6.05 & 0.94 & 0.75 \\
& $\mathbf{6}$ & $\mathbf{5 1}$ & $\mathbf{4 2}$ & $\mathbf{5 1}$ & $\mathbf{5 1}$ \\
\hline FCBD & 86.68 & 4.03 & 8.96 & 0.33 & 0.01 \\
& $\mathbf{5 1}$ & $\mathbf{4 2}$ & $\mathbf{5 1}$ & $\mathbf{4 1}$ & $\mathbf{4 2}$ \\
\hline Stage I BC & 94.45 & 2.58 & 2.78 & 0.19 & $<0.01$ \\
& $\mathbf{2 2}$ & $\mathbf{4 2}$ & $\mathbf{4 2}$ & $\mathbf{4 3}$ & $\mathbf{2 6}$ \\
\hline Stage II BC & 96.56 & 2.06 & 1.22 & 0.15 & $<0.01$ \\
& $\mathbf{3 8}$ & $\mathbf{2 6}$ & $\mathbf{2 6}$ & $\mathbf{2 6}$ & $\mathbf{2 6}$ \\
\hline Stage III BC & 97.62 & 1.43 & 0.45 & 0.07 & $<0.01$ \\
& $\mathbf{5 4}$ & $\mathbf{1 0}$ & $\mathbf{1 0}$ & $\mathbf{1 0}$ & $\mathbf{2 6}$ \\
\hline Kruskal - Wallis & $16.33 ;$ & $16.33 ;$ & $16.33 ;$ & $16.12 ;$ & $16.92 ;$ \\
test (H) & $\mathbf{p = 0 . 0 0 2 6}$ & $\mathbf{p}=\mathbf{0 . 0 0 2 6}$ & $\mathbf{p = 0 . 0 0 2 6}$ & $\mathbf{p}=\mathbf{0 . 0 0 2 9}$ & $\mathbf{p = 0 . 0 0 2}$ \\
\hline
\end{tabular}

decreased life span [15]. Also it may be explained by death of endothelial cells through apoptosis for facilitation of metastasis with loss of vascular wall integrity and consequent hemolysis [16].

The fourth maximum of the spectra of fluorescence excitation (at $335 \mathrm{~nm}$ ) reflects absorption of collagen in breast tissue [17].

Fluorescence spectra of histological samples are also different for benign and malignant breast diseases and changes during tumor growth. They have two maxima (335 and $420 \mathrm{~nm}$ ) and depicted on Fig. 2f. Fluorescence at $420 \mathrm{~nm}$ could be defined by two fluorophores such as NADH and vitamin B6 [18]. Since fluorescence and absorption spectra of biological compounds are wide, we can partially see fluorescence of collagen excited to it's absorption border. For FA and FCBD fluorescence of collagen may be remarkable due to its high concentration is stroma with lack of epithelial cells. In $\mathrm{BC}$ ratio between parenchyma and stroma changes due to increase of epithelial cells amount (Fig. 2 a-e). The picture shows that at $1^{\text {st }}$ stage of $\mathrm{BC}$ around fragments of connective tissue there are pleomorphic epitheliocytes and adipocytes. Thus, at $1^{\text {st }}$ stage BC the total fluorescence from collagen, vitamin $\mathrm{B} 6$ and $\mathrm{NADH}$ is visible. For $\mathrm{BC}$ on $2^{\text {nd }}$ stage impact of fluorescence from vitamin $\mathrm{B} 6$ and $\mathrm{NADH}$ is remarkable due to increase of proliferative activity of the cells. On the $3^{\text {rd }}$ stage of BC there is formation of rosette-like structures and tissue is getting compact due to increase of cells amount per square unit; adipose tissue diminishes (Fig. 2e). Concentration of collagen decreases under the influence of collagenases during tumor invasion and metastasing [19], and vitamin B6 gradually disappears from the tumorous tissue [20]. For this reason, the square of maximum at $420 \mathrm{~nm}$ gradually decreases for $3^{\text {rd }} \mathrm{BC}$ stage. The low level of vitamin B6 in blood was detected in many investigations for patients with advanced $\mathrm{BC}[20,21]$. Peak at $335 \mathrm{~nm}$ is defined by tryptophan and tyrosine-containing peptides [18].

Element analysis detected lower oxygen concentration in $\mathrm{BC}$ tissue on the $1^{\text {st }}$ stage, comparing with BBD (Table 3), with abrupt decrease of its concentration during cancer progression. This is the result of increasing hypoxia influence due to dysbalance between malignant cells proliferation and neoangiogenesis [7].

Previous investigations have shown protective effect of selenium against malignancies [22, 23]. The fact is also confirmed by our data (Table 3). The highest selenium concentration was detected in FA only, when selenium concentration in FCBD and BC was beyond the limit of the experimental device sensitivity. This fact may demonstrate higher potential for malignant transformation of FCBD, than FA.

\section{Conclusion}

In the article we demonstrated the theoretical substantiation for further improvement of optical techniques of breast cancer diagnostics based on biochemical atypism. These data may be useful in differential diagnostics of different breast pathologies or even become a screening instead of histological examination as cheaper and quicker method.

\section{Disclosures}

The authors declare that there are no conflicts of interest related to this article.

\section{Acknowledgments}

Authors greatly thank Dr. M.V. Ovechkin for his help. The work was particularly supported by president fellowship SP-273.2015.4 and Ministry of science and education of Orenburg region of Russia. 